\title{
An Academic Ophthalmology Curriculum as a Model for Introducing Preprofessional Students to Careers in Ophthalmology
}

\author{
Tony Succar, PhD, MScMed(OphthSc) ${ }^{1,2}$ Virginia A. Lee ${ }^{3}$ Christopher Karmonik $^{3}$
}

Andrew G. Lee, $\mathrm{MD}^{3,4,5,6,7}$

${ }^{1}$ Massachusetts Eye and Ear, Harvard Medical School, Boston, Massachusetts

${ }^{2}$ Discipline of Ophthalmology, Save Sight Institute, The University of Sydney, Sydney, Australia

${ }^{3}$ Department of Ophthalmology, Blanton Eye Institute, Houston Methodist Hospital, Houston, Texas

${ }^{4}$ Departments of Ophthalmology, Neurology, and Neurosurgery, Weill Cornell Medicine, New York, New York

${ }^{5}$ Department of Ophthalmology, University of Texas Medical Branch, Galveston, Texas

${ }^{6}$ Department of Ophthalmology, University of Texas MD Anderson Cancer Center, Houston, Texas

${ }^{7}$ Department of Ophthalmology, The University of lowa Hospitals and Clinics, lowa City, lowa

J Acad Ophthalmol 2022;14:e45-e51.
Address for correspondence Andrew G. Lee, MD, Houston Methodist Hospital, Bellaire, TX 77401 (e-mail: aglee@houstonmethodist.org).

\begin{abstract}
Keywords

- ophthalmology

- education

Ophthalmology is one of the most rewarding and fulfilling medical careers in medicine due to the broad practice scope (including a combination of medicine and surgery); patient population (treatment of pediatric and adult patients); diverse patient and pathology mix (healthy eye exams, refractions, and pathology); high patient and provider satisfaction rates; and highly specialized technology and treatments. Unfortunately, academic exposure to ophthalmology as a career in medical school curricula has had a global decline for decades. While most of the evidence-based interventions found in the literature have resulted in enhanced educational outcomes, ophthalmology exposure should be initiated earlier which provided an impetus for developing and implementing a structured curriculum for introducing preprofessional students to careers in ophthalmology. Educational programs offered in the pipeline from high school to college can reach students who are still undecided about higher education and career choices, thus providing an opportunity for increasing the numbers of students in medical and health professions. We describe a structured, academic curriculum model for pregraduate and undergraduate students to enhance interest and to increase academic exposure to basic clinical, research, and educational domains in ophthalmology. The Houston Methodist Hospital (HMH) Academic Institute offers an unparalleled 10-week summer student research program that matches $\mathrm{HMH}$ faculty members with students from multiple levels (e.g., high school, college
\end{abstract}

received

September 24, 2021 accepted after revision November 24, 2021
DOI https://doi.org/ $10.1055 / \mathrm{s}-0042-1743413$. ISSN 2475-4757.

\footnotetext{
(C) 2022. The Author(s).

This is an open access article published by Thieme under the terms of the Creative Commons Attribution-NonDerivative-NonCommercial-License, permitting copying and reproduction so long as the original work is given appropriate credit. Contents may not be used for commercial purposes, or adapted, remixed, transformed or built upon. (https://creativecommons.org/ licenses/by-nc-nd/4.0/)

Thieme Medical Publishers, Inc., 333 Seventh Avenue, 18th Floor, New York, NY 10001, USA
} 
undergraduates, and medical school). Students undergo prerequisite virtual training; attend weekly didactic lectures given by mentors, invited speakers, and other local leaders; shadow health care providers in active clinical settings as observers; participate in active research projects; present at local conferences; and are encouraged to eventually publish their work. We describe the structured curriculum from our first Summer Internship Program for High Schoolers in ophthalmology. To our knowledge an ophthalmology internship program for preprofessional students has not been previously published in the literature.

Ophthalmology is one of the most rewarding and fulfilling medical careers in medicine due to the broad practice scope (including a combination of medicine and surgery); patient population (treatment of pediatric and adult patients); diverse patient and pathology mix (healthy eye exams, refractions, and pathology); high patient and provider satisfaction rates; and highly specialized technology and treatments.

Unfortunately, academic exposure to ophthalmology as a career in medical school curricula has had a global decline for decades. Two recent literature reviews documented both the scope and severity of this decline in ophthalmology experience and exposure in medical schools. ${ }^{1,2}$ This negative trend has impacted medical student confidence and proficiency in core ophthalmic clinical skills and knowledge, but an additional unfortunate side effect has been decreased exposure to opportunities for career development in ophthalmology.

Multiple educational countermeasures and other strategies have been proposed at the medical school level to try and mitigate or reverse the decline in ophthalmic exposure and training. These educational strategies have included development of a competency-based curriculum, ${ }^{3}$ team-based learning modules, ${ }^{4}$ integrated teaching, ${ }^{5}$ short one- ${ }^{6}$ and ten-day ${ }^{7}$ focused training programs, community vision projects through mobile eye clinics, ${ }^{8}$ and virtual ophthalmology clinics and learning environments. ${ }^{9-12}$

More recently, Okaka et al described a strategy to increase ophthalmology exposure by utilizing medical student-run free clinics which primarily service the uninsured, as a unique way for medical students to gain hands-on exposure to ophthalmology. ${ }^{13}$ Furthermore, in response to coronavirus disease 2019 (COVID-19) pandemic several educational strategies were implemented with modified curricula. ${ }^{14}$ Wendt et al developed a Virtual Ophthalmology Rotation to allow students to continue their ophthalmic education remotely in both completely virtual and hybrid learning environments; to conduct and present research projects from home; and to network with faculty and prepare for residency applications via Internet platforms. ${ }^{15}$ Corson and Wallace also developed and implemented a summer ophthalmology research experience for medical students during the COVID-19 pandemic. ${ }^{16}$

While most of the evidence-based interventions found in the literature have resulted in enhanced educational outcomes, ophthalmology exposure should be initiated earlier which provided an impetus for developing and implementing a structured curriculum for introducing preprofessional students to careers in ophthalmology. Educational programs offered in the pipeline from high school to college can reach students who are still undecided about postsecondary education and career choices. ${ }^{17}$ For instance, biomedical programs developed for students during their high school years, can help address the shortage of health professionals because these are the years when the life sciences and physical sciences are taught and when students' interest in health careers may start to develop in a meaningful way. ${ }^{17}$ Moreover, the college admissions process is most relevant to high school students when they are taking college placement tests and applying to colleges. ${ }^{17}$

We describe a structured, academic curriculum model for pregraduate and undergraduate students to enhance interest and to increase academic exposure to basic clinical, research, and educational domains in ophthalmology. To our knowledge an ophthalmology internship program for preprofessional students has not been previously published in the literature.

\section{Methods}

The Houston Methodist Hospital (HMH) Academic Institute offers an unparalleled 10-week summer student research program that matches $\mathrm{HMH}$ faculty members with students from multiple levels (e.g., high school, college undergraduates, and medical school). Students undergo prerequisite virtual training; attend weekly didactic lectures given by mentors, invited speakers, and other local leaders; shadow health care providers in active clinical settings as observers; participate in active research projects; present at local conferences; and are encouraged to eventually publish their work. The HMH internship consists of three programs: the Summer Undergraduate Research Internship (for undergraduate students interested in translational research); the Rosenberg Summer Surgical Fellowship (for undergraduate students interested in surgical shadowing); and the Summer Internship Program for High Schoolers (for high school students over the age of 16 interested in translational research). We describe the structured curriculum from our first Summer Internship Program for High Schoolers in ophthalmology. 


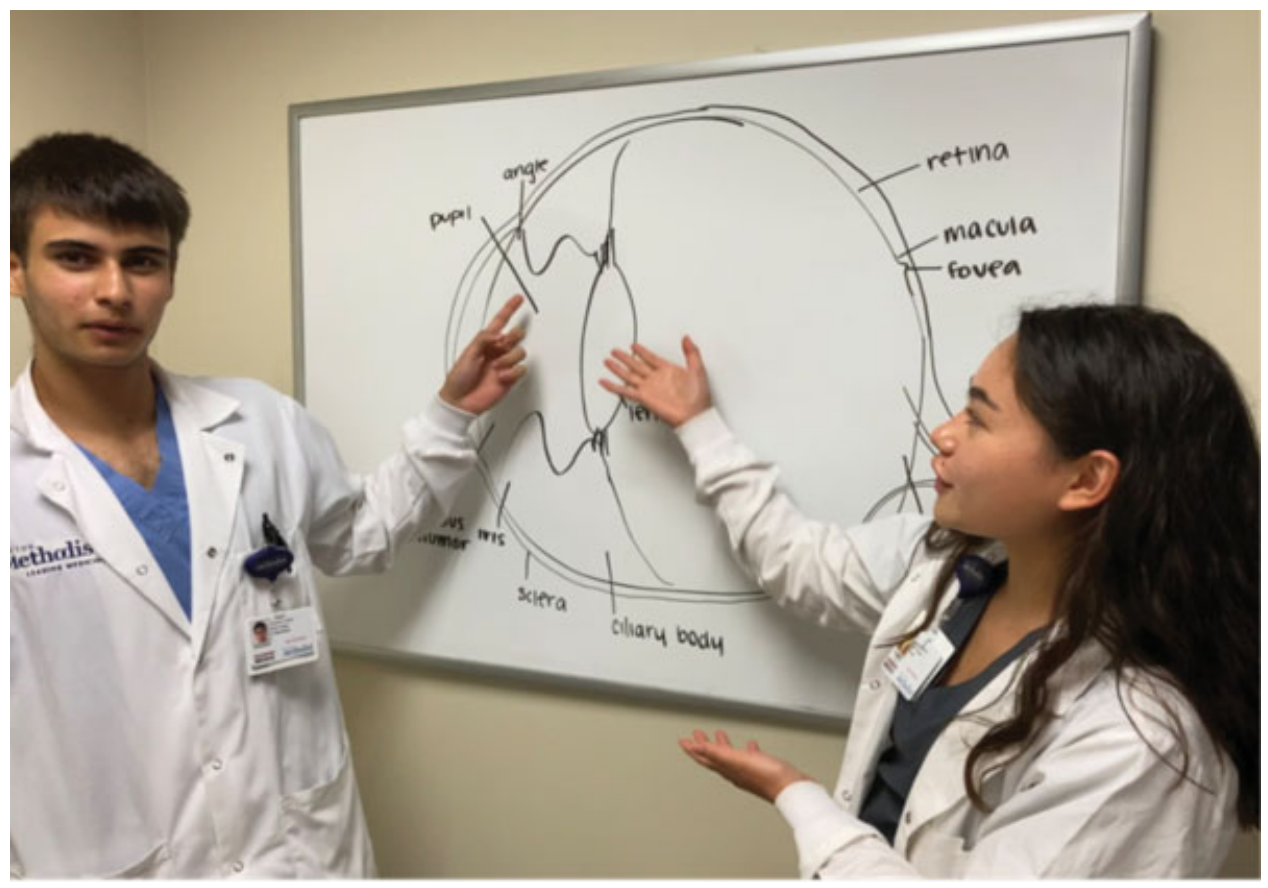

Fig. 1 Filming the YouTube Eyewonder video.

\section{Results}

The HMH summer interns participated in direct observation of academic clinical neuro-ophthalmology in a realworld clinical setting at the Blanton Eye Institute, HMH. The HMH Academic Institute provided all of the "front end" logistics including marketing of the program, public relations, and outreach to schools, Web site presence, program description, and application and candidate selection process. The HMH Academic Institute also provided the hospital orientation, standardized online didactics for clinical research and medical ethics training, candidate background checks and drug screening, photo identification, and badging. All of the above services, staff, and infrastructure was preexisting at the hospital level and provided as in-kind services from the program and thus the Department of Ophthalmology bore no cost or administrative burden for our program.

The learners learned about the doctor-patient relationship, medical professionalism, systems-based practice, communication and interpersonal skills, and practice-based learning. They participated in daily "peer-to-peer" and "peer to near-peer" teaching and learning activities. Examples of "peer-to-peer" teaching and learning include fellows answering questions during our Socratic method learning sessions and thus indirectly teaching other fellows and residents about correct or incorrect answers in real time. Other examples include resident presentations at ophthalmology grand rounds (peer-to-peer) under the supervision of the faculty member who acts as moderator for the session but did not necessarily create the content for the case presentation or discussion slides. In contrast, "peer to near-peer" includes residents and medical students teaching our HMH high school interns about topics that these "peers" and "near-peers" actually have more experience and expertise (e.g., how to dress professionally in the clinic, how to introduce yourself to patients as a nonphysician). Peer to near-peer teaching and learning also frees the faculty member from lower level educational tasks.

In the realm of graduate medical education, they leveraged a preexisting online digital platform (Neuro-Ophthalmology with Dr. Andrew G. Lee [NODAL]) on YouTube and created a novel and unique Web series (EyeWonder) aimed at a peer (high school and college level) target audience (- Figs. 1 and 2). A summary of views, comments, and subscribers for EyeWonder analytics is outlined in -Fig. 3. These short videos provide an adolescent learner audience with easy to follow, short, videos on selected and requested topics in a YouTube format. The learners also contextualized specific clinical cases and learned valuable presentation communication skills by presenting at the Departmental Weekly Ophthalmology Grand Rounds Conference. In the domain of clinical research, the learners completed Institutional Review Board (IRB) applications for two research projects and completed 4 to 5 hours of learning modules on research ethics (e.g., Helsinki) and research protections for human subjects. The learners participated in virtual and real meetings about active research projects in neuro-ophthalmology including "Artificial Intelligence to Detect Optic Disc Abnormalities by Hand-held Fundus Photography"; "Trends in antiVEGF use in ophthalmology during the COVID19 pandemic"; and "Negative Pressure Goggles to Assess Spontaneous Venous Pulsations." Learners participated in medical research projects and contributed alongside medical students to coauthor several EyeWiki articles (American Academy of Ophthalmology). The learners authored EyeWiki on the following topics: polyarteritis nodosa, painful tic convulsif, and bilingual aphasia. 


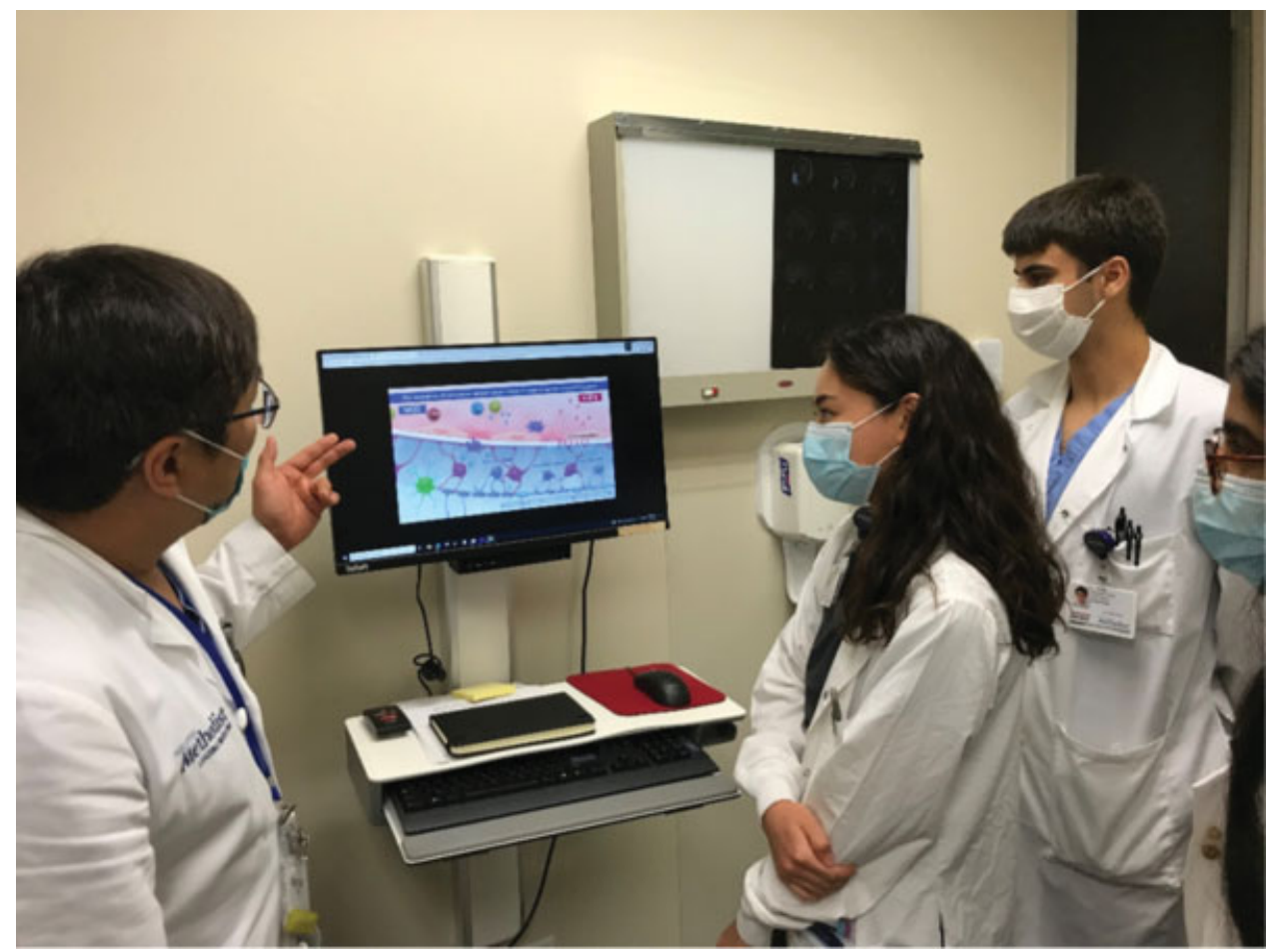

Fig. 2 Learning about the basics of neuroimmunology.

\section{Discussion}

Academic medicine relies heavily upon the "apprenticeship model" for clinical training. High school students interested in medicine as a career have few opportunities for real-world exposure to the medical field. An introduction to all three legs of the tripartite mission of an academic medical center: medical education, clinical and biomedical research, and patient care, is critical to understanding the nature and workings of medicine. Over the course of the HMH Summer Research Internship, we constructed and implemented a program that incorporated direct clinical experience, the basics of clinical research, and novel platforms for virtual peer-to-peer medical education. The structured curriculum included hands-on experience with the IRB application process for research; creating EyeWiki articles; and developing a YouTube educational platform for young learners.

This structured, academic curriculum is specifically aimed at pregraduate and undergraduate students interested in potential careers in ophthalmology to create and sustain a pipeline of potential candidates starting at an earlier point in training. Our program benefits from direct participation and financial support from a major academic medical center $(\mathrm{HMH})$ in a large urban environment (Texas Medical Center, Houston, TX).

We recognize, however, that there is variability in available resources and that our model may not be completely generalizable. Nevertheless, other similar medical, health care, and scientific programs have been described. The Stanford Medical Youth Science Program ${ }^{17}$ is a biomedical pipeline program that seeks to diversify the health profes- sions by providing academic enrichment in the medical sciences and college admissions support to very low-income high school students. Each summer 24 students are recruited from over 250 California high schools for the 5-week residential program, led by 10 undergraduate students. ${ }^{17}$ Participants divide their time between classroom instruction, anatomy practicums, hospital field placements, research projects, and college admissions advising. This program, distinguished by direct participation in the sciences, strong mentoring, college admissions preparation, and long-term career guidance, has been highly successful in reaching lowincome students and preparing them for medical and other careers. $^{17}$

To better prepare students for future careers at the interdisciplinary interface, Enderling et al identified a need to educate junior and senior high school students about integrating mathematical and biological skills, through the lens of mathematical oncology, known as the High school Internship Program in Integrated Mathematical Oncology (HIP IMO) at Moffitt Cancer Center. ${ }^{18}$ Modern cancer research, and the wealth of data across multiple spatial and temporal scales, has created the need for researchers that are well versed in the life sciences (cancer biology, developmental biology, immunology), medical sciences (oncology), and natural sciences (mathematics, physics, engineering, computer sciences). ${ }^{18}$ College undergraduate education traditionally occurs in disciplinary silos, which creates a steep learning curve at the graduate and postdoctoral levels that increasingly bridge multiple disciplines. Numerous colleges have begun to embrace interdisciplinary curricula, but students who double major in mathematics (or other 

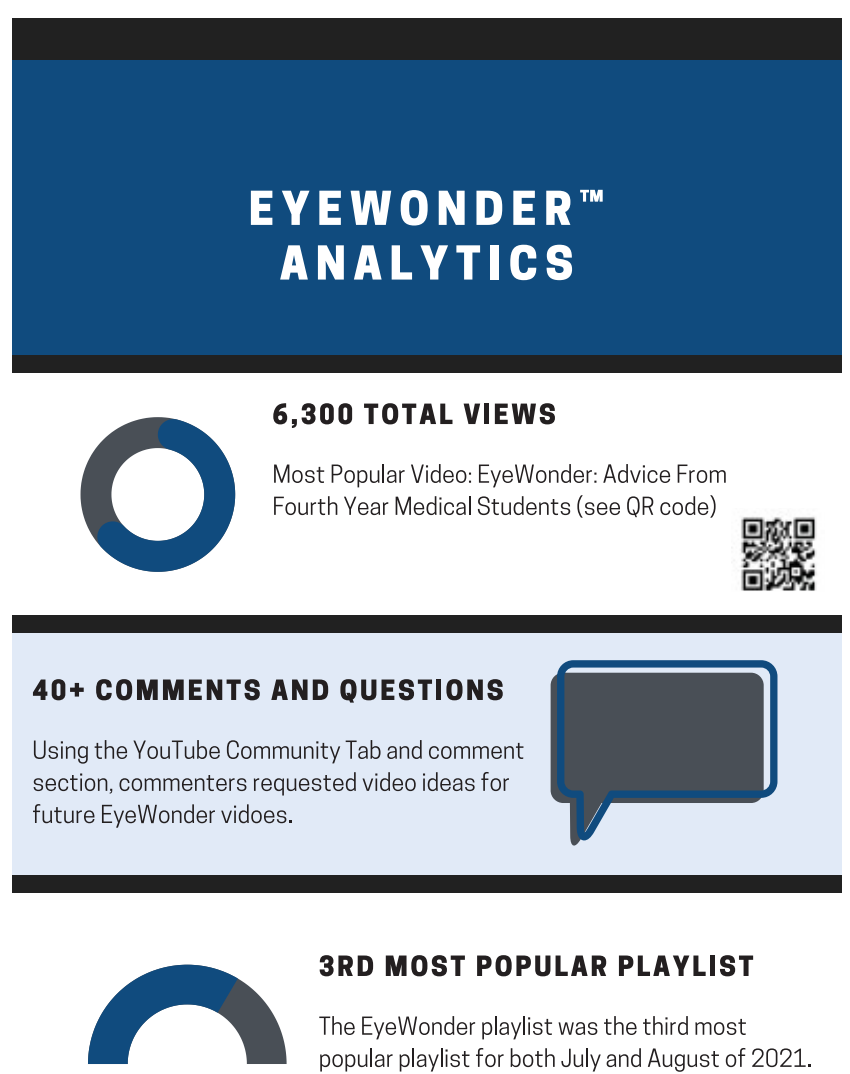

3RD MOST POPULAR PLAYLIST

The EyeWonder playlist was the third most popular playlist for both July and August of 2021.

\section{TOTAL LIKES}

Most Liked Video: EyeWonder (see QR code)

\section{品兴品

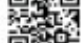 \\ 回得}

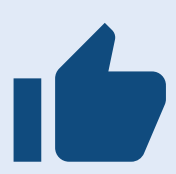

\section{VIDEOS CREATED}

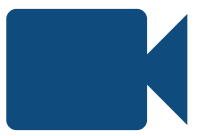

We created these videos using peer suggestions. These videos ranged from topics such as the anatomy of the eye to advice from a medical student!

\section{3,200 SUBSCRIBERS GAINED}

Since the first EyeWonder ${ }^{\text {Tw }}$ video was posted on the Neuro-Ophthalmology with Dr. Andrew $G$. Lee channel, the channel has gained over 3,200 subscribers the University of Michigan Medical School and Cass Technical High School in Detroit which was established with a mission to encourage youth from communities that are underrepresented in medicine to pursue their interests in health care careers. $^{19}$ Students engaged in self-reflective practices prompted by weekly surveys. Four overarching themes were identified: (1) engagement in authentic experiential-learning opportunities; (2) development of professional skills; (3) selfreflection and actualization; and (4) real-world barriers in experiential-learning. ${ }^{19}$ High school students engaged in a variety of different community internships and shared insights that illustrated depth and diversity of understanding health in their community. Their reflections illustrate the added value of experiential-education in pipeline programs. ${ }^{19}$

The Student Career Opportunity Outreach Program (SCOOP) aimed to expose high school students to the nursing profession and entice them to enter nursing. ${ }^{20}$ For over 13 years, SCOOP has offered an internship program to high school students. ${ }^{21}$ A survey was developed to connect with former participants with the goal to gather information about their career choices and whether the program successfully recruited high school students into the nursing profession at their hospital or elsewhere. ${ }^{21}$ Participants reported having a remarkable experience with regard to career definition, personal growth and transformation, developing a work ethic, and knowledge acquisition regarding the health care environment. For many students, being a part of the program reinforced the idea of becoming a nurse. For other students, it may have influenced them to change their career choice to nursing. Eleven former participants have been hired as staff nurses in their institution, which is one indicator of success for the program. ${ }^{21}$

McMiller et al described an 8-week summer Young Scientist in Training internship program involving middle and high school students. This program exposed students to current basic research in molecular genetics, while introducing or reinforcing principles of the scientific method and demonstrating the uses of mathematics and chemistry in biology. ${ }^{22}$ At the end of the program, teams prepared posters detailing their accomplishments, and presented their findings to parents and faculty members during a mini symposium. By the end of the eighth week, all interns had significantly increased their confidence in performing basic mathematical calculations. Students had increased their knowledge with the chemical elements, calculating formula weight, making simple solutions, and they were able to present their research data to their peers. ${ }^{22}$

In response to the COVID-19 pandemic, Lalish et al, developed a novel remote high school program for the 2020-2021 academic school year-the Explorers Virtual Internship, a virtual internship program for 10th to 12th graders in which interns are paired with scientist mentors. Their aims were to provide interns with a meaningful research experience under the mentorship of a scientist, interest them in science, technology, engineering, and mathematics (STEM) careers, and give students a sense of belonging in the field of biomedicine. Previously, the Explorers program was a 2week in-person summer outreach program aimed at rising 
10th to 11 th graders from underrepresented backgrounds in STEM. ${ }^{23}$ In-person program in the summer of 2020 was not available and instead the program held a scaled-down virtual program (Virtual Explorations in Cancer Research [VECR]) that met for 3 hours per week for 6 weeks. ${ }^{23}$ The COVID-19 pandemic restrictions were causing major disruptions to the lives of high schoolers, especially those from marginalized communities, it was found that students were more eager to stay connected and make new connections with scientists and like-minded students. ${ }^{23}$ Personal connections and research experiences were more valuable, thus, instead of reducing programming in response to the pandemic, there was a need to create more opportunities for student engagement. $^{23}$

\section{Limitations}

We recognize that the strength of our program is that it is novel and unique and reaches a specific target audience (high school students) in a large urban environment within an academic medical center (the Texas Medical Center). This strength, however, is also the main weakness of our report as this was the inaugural HMH Summer Internship Program for high school students in ophthalmology. We recognize that this work is qualitative and descriptive only and further data on the long-term effectiveness of the program in terms of objective outcome measures will require continued study over time. We hope to collect longitudinal data on the performance of future summer high school interns and to assess their confidence and satisfaction with the program as well as determine if our interns eventually went to medical school and perhaps more importantly ultimately chose ophthalmology as a career.

\section{Conclusion}

We describe a structured academic curriculum designed to provide exposure to various aspects of clinical care, education, and research in ophthalmology. Our program benefits from an existing robust infrastructure within a designated $\mathrm{HMH}$ summer research internship program that is specifically designed for preprofessional students at multiple levels (high school, undergraduate, and graduate). The stated goal of the program is to create a sustainable pipeline of academically minded students to continue with multiyear summer participation at higher levels of training to recruit highquality applicants to ophthalmology as a career downstream. This was a pilot program for HMH with only two high school aged students in the inaugural summer internship program. We hope that our model might be helpful to other likeminded and interested ophthalmology programs and eventually generalizable to other programs in our local medical center and also across the country. To our knowledge, this is the first such high school level program described for ophthalmology in the English language ophthalmic literature.

Conflict of Interest

None declared.

\section{References}

1 Succar T, Grigg J, Beaver HA, Lee AG. A systematic review of best practices in teaching ophthalmology to medical students. Surv Ophthalmol 2016;61(01):83-94

2 Succar T, Grigg J, Beaver HA, Lee AG. Advancing ophthalmology medical student education: international insights and strategies for enhanced teaching. Surv Ophthalmol 2020;65(02): 263-271

3 Succar T, McCluskey P, Grigg J. Enhancing medical student education by implementing a competency-based ophthalmology curriculum. Asia Pac J Ophthalmol (Phila) 2017;6(01):59-63

4 Altintas L, Altintas O, Caglar Y. Modified use of team-based learning in an ophthalmology course for fifth-year medical students. Adv Physiol Educ 2014;38(01):46-48

5 Tsinopoulos IT, Symeonidis C, Tsaousis KT, et al. Contribution of integrated teaching in the improvement of an undergraduate ophthalmology curriculum. Adv Med Educ Pract 2014; 5:433-437

6 Quillen DA, Cantore WA. Impact of a 1-day ophthalmology experience on medical students. Ophthalmology 2006;113(12): 2307-2309

7 Waring GO III, Walters RF. Curriculum for a 10-day medical student clerkship in ophthalmology. J Med Educ 1976;51(09): 772-774

8 Byrd JM, Longmire MR, Syme NP, Murray-Krezan C, Rose L. A pilot study on providing ophthalmic training to medical students while initiating a sustainable eye care effort for the underserved. JAMA Ophthalmol 2014;132(03):304-309

9 Succar T, Grigg J. A new vision for teaching ophthalmology in the medical curriculum: The Virtual Ophthalmology clinic. In: Steel $\mathrm{CH}$, Keppell MJ, Gerbic P, Housego S, eds. Curriculum, Technology \& Transformation for an Unknown Future. Proceedings ascilite Sydney; 2010:944-947

10 Succar T, Zebington G, Billson F, et al. The impact of the Virtual Ophthalmology Clinic on medical students' learning: a randomised controlled trial. Eye (Lond) 2013;27(10):1151-1157

11 Succar T, Grigg J. "The Role of Educational Technology in Promoting the Inclusion of Rural Clinical Schools for Ophthalmology Teaching Using Virtual Patients.". In: Hoffman J, Blessinger P, Makhanya M, eds. Strategies for Fostering Inclusive Classrooms in Higher Education: International Perspectives on Equity and Inclusion (Innovations in Higher Education Teaching and Learning. Vol. 16 Bingley, UK: Emerald Publishing Limited; 2019:167-181

12 He B, Tanya S, Sharma S. Perspectives on virtual ophthalmology education among Canadian medical students. Can J Ophthalmol 2021;56(03):208-209

13 Okaka Y, Meah YS, Fallar R, Chadha N. Ophthalmology services at student-run free clinics: a national survey. J Natl Med Assoc 2021; 113(04):431-435

14 Succar T, Beaver HA, Lee AG. Impact of COVID-19 pandemic on ophthalmology medical student teaching: educational innovations, challenges, and future directions. Surv Ophthalmol 2021: S0039-6257(21)00098-9

15 Wendt S, Abdullah Z, Barrett S, et al. A virtual COVID-19 ophthalmology rotation. Surv Ophthalmol 2021;66(02):354-361

16 Corson TW, Wallace DK. Modulating a summer ophthalmology research experience for medical students during the COVID-19 pandemic. Int J Med Educ 2021;12:34-35

17 Winkleby MA. The Stanford Medical Youth Science Program: 18 years of a biomedical program for low-income high school students. Acad Med 2007;82(02):139-145

18 Enderling H, Altrock PM, Andor N, et al. High School Internship Program in Integrated Mathematical Oncology (HIP IMO): fiveyear experience at Moffitt Cancer Center. Bull Math Biol 2020;82 (07):91

19 Kana LA, Noronha C, Diamond S, et al. Experiential-Learning Opportunities Enhance Engagement in Pipeline Program: 
a qualitative study of the Doctors of Tomorrow Summer Internship Program. J Natl Med Assoc 2020;112(01):15-23

20 Brostoff M, Arsenault L, Phipps B, Powers D. Nursing Career Outreach Program for High School Students: get the scoop on 21st-century recruitment. Am J Nurs 2005;105(04):72A-72H

21 Gómez E, Brostoff M. Helping High School Students Explore Nursing Careers in a Summer Internship Program. J Nurses Prof Dev 2018;34(03):133-141
22 McMiller T, Lee T, Saroop R, Green T, Johnson CM. Middle/high school students in the research laboratory: a summer internship program emphasizing the interdisciplinary nature of biology. Biochem Mol Biol Educ 2006;34(02):88-93

23 Lalish KM, Stromholt S, Curtis N, Chowning JT. Explorers Virtual Internship: fostering rightful presence and sense of belonging in an online high school internship program. J STEM Outreach 2021; 4(02):. Doi: $10.15695 /$ jstem/v4i2.07 